\title{
Fisetin Alleviates Hepatic and Adipocyte Fibrosis and Insulin Resistance in Diet-Induced Obese Mice
}

\author{
Myung-Sook Choi ${ }^{1, *}$ Ji-Young Choi ${ }^{2, *, \dagger}$ and Eun-Young Kwon ${ }^{1}$ \\ ${ }^{1}$ Department of Food Science and Nutrition, Kyungpook National University, Daegu, Korea. \\ ${ }^{2}$ Graduate School of Pharmaceutical Sciences, College of Pharmacy, Ewha Womans University, Seoul, Korea.
}

\begin{abstract}
The present study aimed to investigate the protective role of the flavonoid fisetin (FI) on inflammationmediated metabolic diseases, especially tissue fibrosis and insulin resistance (IR) in high-fat diet (HFD)-induced obese mice. C57BL/6J mice were fed with normal-fat diet, HFD (40 kcal\% fat), or HFD +0.02\% (w/w) FI for 16 weeks. Dietary FI supplementation improved hepatic steatosis by restricting lipogenesis, while promoting lipolysis in the liver. FI also prevented adiposity via an increase in the expression of genes involved in FA oxidation and a decrease in the expression of genes involved in lipogenesis in white adipose tissue. In addition, FI increased brown adipose tissue (BAT) and skeletal muscle weights, thermogenic gene mRNA expression in BAT, and tricarboxylic acid cycle-related gene expression in skeletal muscle, which may be linked to the prevention of nonalcoholic fatty liver disease as well as adiposity. Moreover, FI supplementation decreased excessive reactive oxygen species production by increasing paraoxonase activity, adipokine dysregulation, proinflammatory cytokine production, and extracellular matrix amassment in the liver. FI supplementation ameliorated IR, in part, by normalizing pancreatic islet dysfunction, and it declined hepatic gluconeogenesis and proinflammatory responses. Taken together, the present findings indicate that FI can protect against HFD-induced inflammation-mediated disorders, including fibrosis and IR.
\end{abstract}

\section{KEYWORDS: • adiposity $\bullet$ extracellular matrix $\bullet$ fisetin $\bullet$ insulin resistance $\bullet$ liver fibrosis $\bullet N A F L D$}

\section{INTRODUCTION}

$\mathbf{O}$ BESITY IS A complex disease that is closely associated with the increased risk of metabolic disorders, especially nonalcoholic fatty liver disease (NAFLD), hepatic fibrosis, insulin resistance (IR), and type II diabetes. Molecular links between obesity, NAFLD, and hepatic fibrosis may consist of extracellular matrix (ECM) accumulation and chronic inflammation within the liver, although it is not yet fully understood. ${ }^{1-3}$ Obesity triggers adipocyte hypertrophy, which can contribute to low-chronic inflammation and the production and accumulation of ECM, resulting in the pathogenesis of fibrosis. ${ }^{4}$ Moreover, accumulated evidence indicates that the inflammatory reaction is complex and often entails reactive oxygen species (ROS). Oxidative stress-induced by ROS increases the proinflammatory cytokine production, and subsequently provokes the fibrogenesis signaling pathways..$^{5}$ More recently, research

\footnotetext{
*These authors contributed equally to this article.

${ }^{\dagger}$ Current affiliation: Department of Food and Nutrition, Chosun University, 309 Pilmundaero, Dong-gu, Gwangju 61452, Republic of Korea.

Manuscript received 28 October 2019. Revision accepted 28 July 2020.

Address correspondence to: Eun-Young Kwon, PhD, Department of Food Science and Nutrition, Kyungpook National University, 1370 Sank-Yuk Dong Puk-Ku, Daegu 41566, Republic of Korea, E-mail: eykwon@knu.ac.kr
}

has been underway to prove the correlation between brown adipose tissue (BAT), skeletal muscle, and NAFLD.$^{6-8}$ As a result, attention is focusing on BAT and skeletal muscle as target organs for treating or preventing NAFLD.

Fisetin (FI, 3,7,3',4'-tetrahydroxyflavone) is a naturally occurring flavonoid found in fruits and vegetables, especially strawberries and blueberries. ${ }^{9}$ FI can suppress the proinflammatory response, with strong antioxidant and antitumor effects. ${ }^{10,11}$ FI has also been demonstrated to have antiobesity and anti-NAFLD properties. ${ }^{12-15}$ In high-fat diet (HFD, $60 \mathrm{kcal} \%$ fat)-fed C57BL/6 mice, intraperitoneal injection with FI for 10 weeks decreased body weight (BW), epididymal white adipose tissue (WAT), serum-free fatty acid (FFA) and leptin concentrations, and liver lipid droplet and hepatocyte steatosis. ${ }^{13}$ In rat models of diet-induced obesity, FI supplementation for 8 weeks ameliorated dietinduced NAFLD by suppressing hepatic lipid accumulation, and mitigating oxidative stress. ${ }^{14,15}$ In addition, FI given by gavage for 20 weeks, restrains HFD (60 kcal\% fat)-induced hepatic inflammation and lipid deposition by downregulating metabolic disorder and excessive liver inflammationassociated TNF- $\alpha$ /RIPK3 axis activation. ${ }^{16}$ However, to date, the effects of this chemical on hepatic fibrosis are not fully elucidated, and the above-mentioned research articles have provided FI using not oral supplementation but intraperitoneal injection or gavage and used unusually HFDs (60 kcal\% fat), which do not reflect human dietary consumption. 
Moreover, little research has been done to investigate the effects of long-term oral supplementation with FI in the development of obesity and its complications. Thus, this study was designed to investigate the metabolic actions of longterm supplementation with dietary FI in HFD-induced obese mice. In particular, we focused on its role in amelioration of obesity-induced inflammation-mediated metabolic disorders, especially liver fibrosis and IR.

\section{MATERIALS AND METHODS}

\section{Experimental animals and diet}

Male 4-week-old C57BL/6J mice ( Jackson Laboratory, Bar Harbor, ME, USA) were individually housed in a pathogenfree barrier facility at a room temperature $\left(22^{\circ} \mathrm{C} \pm 2^{\circ} \mathrm{C}\right)$ and maintained on a 12-h light/dark cycle. Mice were randomly assigned to a normal-fat diet $(n=13)$ group, a HFD $(n=13$; $20 \%$ fat and $1 \%$ cholesterol) group, or HFD with $0.02 \%(\mathrm{w} / \mathrm{w})$ FI (FI, $n=13$; obtained from Sigma-Aldrich, St. Louis, MO, USA) group. The mice were fed each diet and water ad libitum for 16 weeks.

At the end of the diet period, the mice were sacrificed, and then blood samples, liver, WAT of epididymal, perirenal, retroperitoneum, subcutaneous, and interscapular depots, as well as interscapular BAT and skeletal muscle were isolated immediately, weighed, and stored at $-70^{\circ} \mathrm{C}$. The animal study protocols were approved by the Kyungpook National University Ethics Committee (Approval No. KNU 2010-4-14).

\section{Blood analysis}

The plasma FFA (Reagent1: \#434-91795, Reagent2: \#43691995, NEFA Standard: \#270-77000) and phospholipids (\#296-63801) levels were measured using a Wako enzymatic kit (Wako Chemicals, Osaka, Japan). The plasma triglyceride (TG, \#AM157S), total-cholesterol (TC, \#AM202), highdensity lipoprotein cholesterol (HDL-C, \#AM203), glutamic oxaloacetic transaminase (GOT, \#AM103-K), and glutamic pyruvic transaminase (GPT, \#AM102) concentrations were determined using commercial enzymatic kits (Asan Pharm Co., Seoul, South Korea). The levels of plasma apolipoprotein A1 (ApoA1, \#1433501) and B100 (ApoB100, \#1433701; Eiken Chemical Co., Tokyo, Japan), and soluble CD antigen 163 (sCD163, \#MBS903944) and phospholipid transfer protein (PLTP, \#MBS008754) were analyzed using a commercial kit (Mybiosource, San Diego, CA, USA). The atherogenic index (AI) and HDL-C-to-TC ratio (HTR) were calculated as follows: $\mathrm{AI}=(\mathrm{TC}-\mathrm{HDL}-\mathrm{C}) / \mathrm{HDL}-\mathrm{C}$; and HTR $(\%)=\mathrm{HDL}-\mathrm{C} /$ $\mathrm{TC} \times 100$. The levels of plasma insulin, glucagon-like peptide1 (GLP-1), leptin, adiponectin, tumor necrosis factor- $\alpha$ (TNF$\alpha$ ), monocyte chemoattractant protein-1 (MCP-1), interferon $\gamma$ (IFN- $\gamma$ ), interleukin-6 (IL-6), and plasminogen activator inhibitor-1 (PAI-1) were determined using a MILLIPLEX MAP Mouse Metabolic Hormone (GLP-1), Adipokine (insulin, leptin, adiponectin, MCP-1, TNF- $\alpha$ and PAI-1), and Cytokine (IL-6 and IFN- $\gamma$ ) kits (Merck Millipore, Billerica, MA, USA), respectively. Homeostatic model assessment of IR (HOMA-IR) and intraperitoneal glucose tolerance test were calculated and performed as described in our previous studies. ${ }^{17,18}$

\section{Hepatic and fecal lipid contents}

The classical Folch lipid extraction method was used for lipid extraction from liver. ${ }^{19}$ The lipid contents of liver and feces were also determined as described in our previous studies. ${ }^{17,18}$

\section{Hepatic lipid- and glucose-regulating enzyme activities}

Hepatic cytosolic, microsomal, and mitochondrial fractions were prepared according to the Hulcher and Oleson method, ${ }^{20}$ and protein levels were determined using the Bradford method. Fatty acid synthase (FAS) ${ }^{21}$ phosphatidate phosphohydrolase ${ }^{22}$ carnitine palmitoyltransferase (CPT) ${ }^{23}$ and $\beta$-oxidation, ${ }^{24}$ 3-hydroxy-3-methyl-glutaryl-coenzyme A reductase (HMGCR), ${ }^{25}$ and acyl-CoA:cholesterol acyltransferase (ACAT) ${ }^{26}$ activities were measured as previously described. Glucose-6-phosphatase (G6Pase) ${ }^{27}$ glucokinase $(\mathrm{GK}){ }^{28}$ phosphoenolpyruvate carboxykinase (PEPCK) ${ }^{29}$ activities, and glycogen ${ }^{30}$ concentrations were also determined as previously described.

\section{Hepatic antioxidant-regulating enzyme activities}

The hepatic $\mathrm{H}_{2} \mathrm{O}_{2}{ }^{31}$ and thiobarbituric acid reactive substance (TBARS) ${ }^{32}$ contains and plasma and hepatic paraoxonase $(\mathrm{PON})^{33}$ activities were measured as previously described.

\section{Morphology of liver, fat, and pancreatic tissues}

Liver and epididymal WAT were fixed in paraformaldehyde/phosphate-buffered saline (PBS) $(10 \% \mathrm{v} / \mathrm{v})$; paraffinembedded sections were stained using hematoxylin and eosin, and Masson's trichrome. The pancreatic tissue samples were fixed in paraformaldehyde/PBS (4\% [v/v]; paraffin-embedded sections were immunochemically stained for insulin. The stained areas were analyzed under an optical microscope (Nikon, Tokyo, Japan) at $200 \times$ magnification.

\section{RNA isolation and microarray analysis}

Liver, epididymal WAT, and gastrocnemius muscle samples were prepared and total RNA extracted. Microarray analysis was analyzed in epididymal WAT and gastrocnemius muscle and then the differentially expressed gene analysis between groups was performed as described previously. ${ }^{17}$

The Kyoto Encyclopedia of Genes and Genomes (KEGG) pathways mapper was consulted for the analysis of gene functions involved in the tricarboxylic acid (TCA) cycle.

\section{Gene expression analysis}

Total RNA of all samples was reverse transcribed to cDNA using a QuantiTect ${ }^{\circledR}$ reverse transcription kit 
(\#205314; Qiagen Gmbh, Hilden, Germany). Real-time RTPCR was performed using the SYBR Green PCR kit (\#204143; Qiagen Gmbh) using the CFX96 ${ }^{\mathrm{TM}}$ real-time system (Bio-Rad, Hercules, CA, USA). The expression level of specific mouse-GAPDH was set as internal controls. The sequences of all primers are listed in Table 1.

\section{Statistical analysis}

Values are represented as means \pm standard error of the mean. Statistical analyses were performed using SPSS software (SPSS, Inc., Chicago, IL, USA). Significance was determined by using the Student's $t$-test.

\section{RESULTS}

Fisetin supplementation prevented adiposity and dyslipidemia

FI-supplement markedly suppressed BW and food efficiency ratio despite the increase in food intake compared with those in the HFD-fed mice (Fig. 1A-C). Moreover, the weights of the epididymal, perirenal, retroperitoneum, visceral and total WAT, excluding interscapular WAT, and the epididymal adipose size in HFD+FI group were significantly decreased (Fig. 1D, E). FI significantly decreased the expression of adipocyte genes involved in lipogenesis (e.g., $P P A R \gamma, S R E B P 1, F A S$, and $S C D 1$ ), whereas it upregulated FA oxidation-related gene (e.g., $C P T 1, C P T 2$, and $C O X 8 \beta$ ) expressions (Fig. 1F).

FI-supplemented mice also significantly decreased plasma levels of TC, AI, ApoB, and ApoB/ApoA ratio, while it markedly increased HTR and ApoA levels compared to HFD group. In addition, FI-supplement significantly decreased plasma PLTP activity than HFD group (Fig. 2).

Fisetin supplementation increased weights of skeletal muscle and BAT, and upregulated the expression of muscle genes involved in the TCA cycle

The mice fed with FI exhibited significant increases in the weight of BAT and skeletal muscle (Fig. 3A, B). In BAT, FI supplementation enhanced thermogenesis-related genes (Ucp1, Ppargcla, Sirt1, Cox8 $\beta$, Cidea, and Tfam) (Fig. 3C). Moreover, FI increased TCA cycle-associated gene expressions, including Dld, Cs, Idh1, Idh2, Suclg1, and Sdhb that were downregulated by HFD (Fig. 3D).

\section{Fisetin supplementation prevented hepatic steatosis} and fibrosis

FI-supplemented mice exhibited a significantly decreased size and number of hepatic lipid droplets, and lower hepatic FA and TG concentrations, as well as liver weights, relative to mice in the HFD group (Fig. 4A-C). Moreover, FI supplementation significantly decreased the activity of enzymes involved in cholesterol synthesis (e.g., HMGCR and ACAT) and lipogenesis (e.g., FA synthase) and gene (e.g., PPAR $\gamma, S R E B P$, and SCDI) expressions, whereas it markedly increased FA oxidation-related
Table 1. Primer Sequences Used for the Reverse Transcription Quantitative PCR

\begin{tabular}{|c|c|c|}
\hline Gene & $\begin{array}{c}\text { Primer } \\
\text { direction }\end{array}$ & Primer sequence \\
\hline \multirow[t]{2}{*}{$G A P D H$} & Forward & 5'-CAAGTTCAACGGCACAGTCAAGG-3' \\
\hline & Reverse & 5'-ACATACTCAGCACCAGCATCACC- $3^{\prime}$ \\
\hline \multirow[t]{2}{*}{$P P A R \gamma$} & Forward & 5'-GAGTGTGACGACAAGATTTG-3' \\
\hline & Reverse & 5'-GGTGGGCCAGAATGGCATCT-3' \\
\hline \multirow{2}{*}{$P G C 1 \alpha$} & Forward & 5'-AAGTGTGGAACTCTCTGGAACTG-3' \\
\hline & Reverse & 5'-GGGTTATCTTGGTTGGCTTTATG-3' \\
\hline \multirow[t]{2}{*}{$P G C 1 \beta$} & Forward & 5'-GGTCCCTGGCTGACATTCAC-3' \\
\hline & Reverse & $5^{\prime}$-GGCACATCGAGGGCAGAG-3' \\
\hline \multirow[t]{2}{*}{ SREBPIa } & Forward & $\begin{array}{l}5^{\prime} \text {-TAGTCCGAAGCCGGGTGGGCGCCGG } \\
\text { CGCCAT- } 3^{\prime}\end{array}$ \\
\hline & Reverse & $\begin{array}{l}\text { 5'-GATGTCGTTCAAAACCGCTGTGTGTCC } \\
\text { AGTTC-3' }\end{array}$ \\
\hline \multirow[t]{2}{*}{$A C C$} & Forward & $5^{\prime}$-GCCTCTTCCTGACAAACGAG- $3^{\prime}$ \\
\hline & Reverse & $5^{\prime}$-TGACTGCCGAAACATCTCTG-3' \\
\hline \multirow[t]{2}{*}{ FAS } & Forward & 5'-GCTGCGGAAACTTCAGGAAAT-3' \\
\hline & Reverse & 5'-AGAGACGTGTCACTCCTGGACTT-3' \\
\hline \multirow[t]{2}{*}{$S C D 1$} & Forward & $5^{\prime}$-CCCCTGCGGATCTTCCTTAT- ${ }^{\prime}$ \\
\hline & Reverse & 5'-AGGGTCGGCGTGTGTTTCT-3' \\
\hline \multirow[t]{2}{*}{$A D R B 3$} & Forward & 5'-ACCAACGTGTTCGTGACT-3' \\
\hline & Reverse & $5^{\prime}$-ACAGCTAGGTAGCGGTCC- $3^{\prime}$ \\
\hline \multirow[t]{2}{*}{ CPT1 } & Forward & $5^{\prime}$-ATCTGGATGGCTATGGTCAAGGTC-3' \\
\hline & Reverse & 5'-GTGCTGTCATGCGTTGGAAGTC-3' \\
\hline \multirow[t]{2}{*}{$C P T 2$} & Forward & 5'-GCCTGCTGTTGCGTGACTG-3' \\
\hline & Reverse & 5'-TGGTGGGTACGATGCTGTGC-3' \\
\hline \multirow[t]{2}{*}{$\operatorname{COX} 8 \beta$} & Forward & 5'-TGTGGGGATCTCAGCCATAGT-3' \\
\hline & Reverse & $5^{\prime}$-AGTGGGCTAAGACCCATCCTG-3' \\
\hline \multirow{2}{*}{$U C P 1$} & Forward & 5'-AGATCTTCTCAGCCGGAGTTT-3' \\
\hline & Reverse & 5'-CTGTACAGTTTCGGCAATCCT-3' \\
\hline \multirow{2}{*}{ SIRT1 } & Forward & $5^{\prime}$-TGTGAAGTTACTGCAGGAGTGTAAA-3' \\
\hline & Reverse & $5^{\prime}$-GCATAGATACCGTCTCTTGATCTGAA-3' \\
\hline \multirow[t]{2}{*}{ CIDEA } & Forward & 5'-TTTCAAACCATGACCGAAGTAGCC-3' \\
\hline & Reverse & $5^{\prime}$-CCTCCAGCACCAGCGTAACC- $3^{\prime}$ \\
\hline \multirow[t]{2}{*}{ TFAM } & Forward & 5'-CAAAAAGACCTCGTTCAGCA-3' \\
\hline & Reverse & 5'-CTTCAGCCATCTGCTCTTCC-3' \\
\hline \multirow[t]{2}{*}{ IRS2 } & Forward & 5'-CCCATGTCCCGCCGTGAAG-3' \\
\hline & Reverse & $5^{\prime}$-CTCCAGTGCCAAGGTCTGAAGG-3' \\
\hline \multirow[t]{2}{*}{ PEPCK } & Forward & $5^{\prime}$-ATCATCTTTGGTGGCCGTAG-3' \\
\hline & Reverse & $5^{\prime}$-ATCTTGCCCTTGTGTTCTGC- $3^{\prime}$ \\
\hline \multirow[t]{2}{*}{$G K$} & Forward & $5^{\prime}-$ CAGGACAGTGGAGCGTGAAGAC- $3^{\prime}$ \\
\hline & Reverse & $5^{\prime}$-TTACAGGGAAGGAGAAGGTGAAGC-3' \\
\hline \multirow[t]{2}{*}{ G6Pase } & Forward & $5^{\prime}$-GGAGGAAGGATGGAGGAAGGAATG-3' \\
\hline & Reverse & 5'-GGTCAGCAATCACAGACACAAGG-3' \\
\hline COL1 & Forward & 5'-A CAGCCGCTTCACCTACAGC-3' \\
\hline & Reverse & 5'-TTTTGTATTCAATCACTGTCTTGCC-3' \\
\hline TIMPI & Forward & 5'-GGTGTGCACAGTGTTTCCCTGTTT-3' \\
\hline & Reverse & 5'-TCCGTCCACAAACAGTGAGTGTCA-3' \\
\hline MMP2 & Forward & $5^{\prime}$-CAGGGAATGAGTACTGGGTCTATT-3' \\
\hline & Reverse & 5'-ACTCCAGTTAAAGGCAGCATCTAC-3' \\
\hline$M M P 3$ & Forward & 5'-ACCAACCTATTCCTGGTTGCTGCT-3' \\
\hline & Reverse & $5^{\prime}$-ATGGAAACGGGACAAGTCTGTGGA-3' \\
\hline MMP9 & Forward & $5^{\prime}$-GGACCCGAAGCGGACATTG-3' \\
\hline & Reverse & 5'-CGTCGTCGAAATGGGCATCT- $3^{\prime}$ \\
\hline TLR4 & Forward & 5'-AAGAGCCGGAAGGTTATTGTG-3' \\
\hline & Reverse & 5'-CCCATTCCAGGTAGGTGTTTC-3' \\
\hline$I L-6$ & Forward & 5'-GAGGATACCACT-CCCAACAGACC-3' \\
\hline & Reverse & 5'-AAGTGCATCATCGTTGTTCATACA-3' \\
\hline
\end{tabular}

ACC, acetyl-CoA carboxylase; ADRB3, $\beta$-3 adrenergic receptor; CIDEA, cell death-inducing DFFA-like effector A; COL1, collagen 1; COX8 $\beta$, cytochrome c oxidase subunit $8 \beta$; GAPDH, glyceraldehyde 3-phosphate dehydrogenase; IRS2, insulin receptor substrate 2; MMP2, matrix metalloproteinase 2; PGC1 $\alpha$, PPAR $\gamma$ coactivator $1 \alpha$; PPAR $\gamma$, peroxisome proliferator-activated receptor $\gamma$; SCD1, stearoyl-CoA desaturase 1 ; SIRT1, sirtuin 1 ; SREBP $1 \alpha$, sterol regulatory elementbinding transcription factor $1 \alpha$; TFAM, transcription factor A, mitochondrial; TIMP1, tissue inhibitors of metalloproteinase 1; TLR4, toll-like receptor 4; UCP1, uncoupling protein 1. 

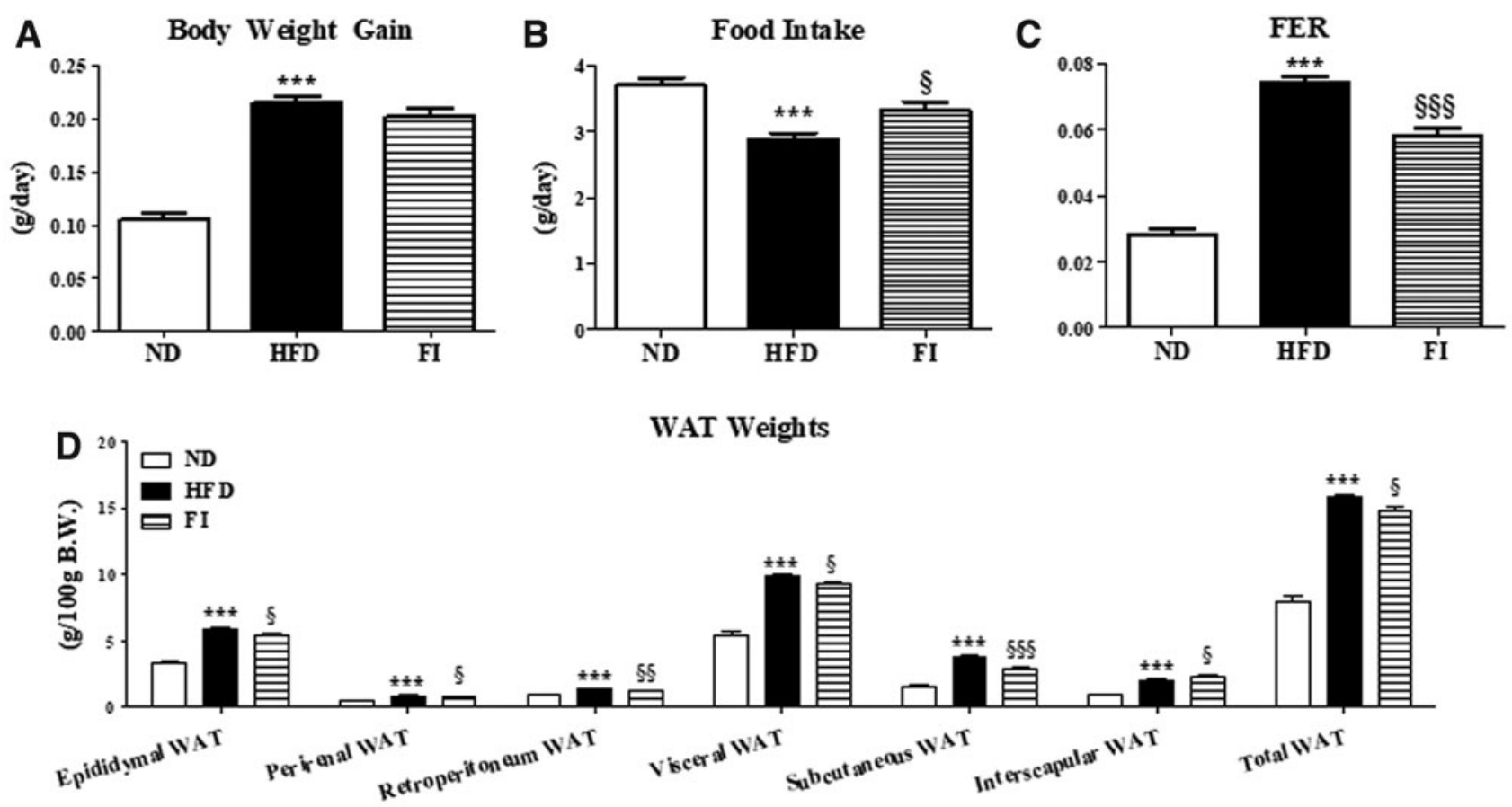

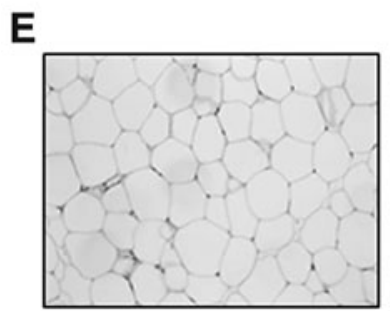

ND
H\&E staining

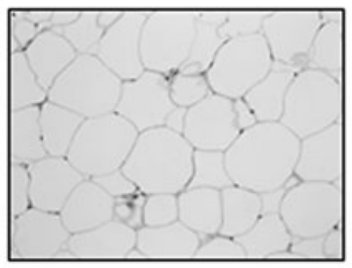

HFD

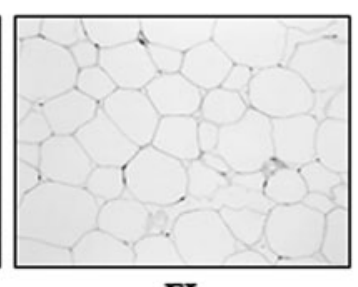

FI
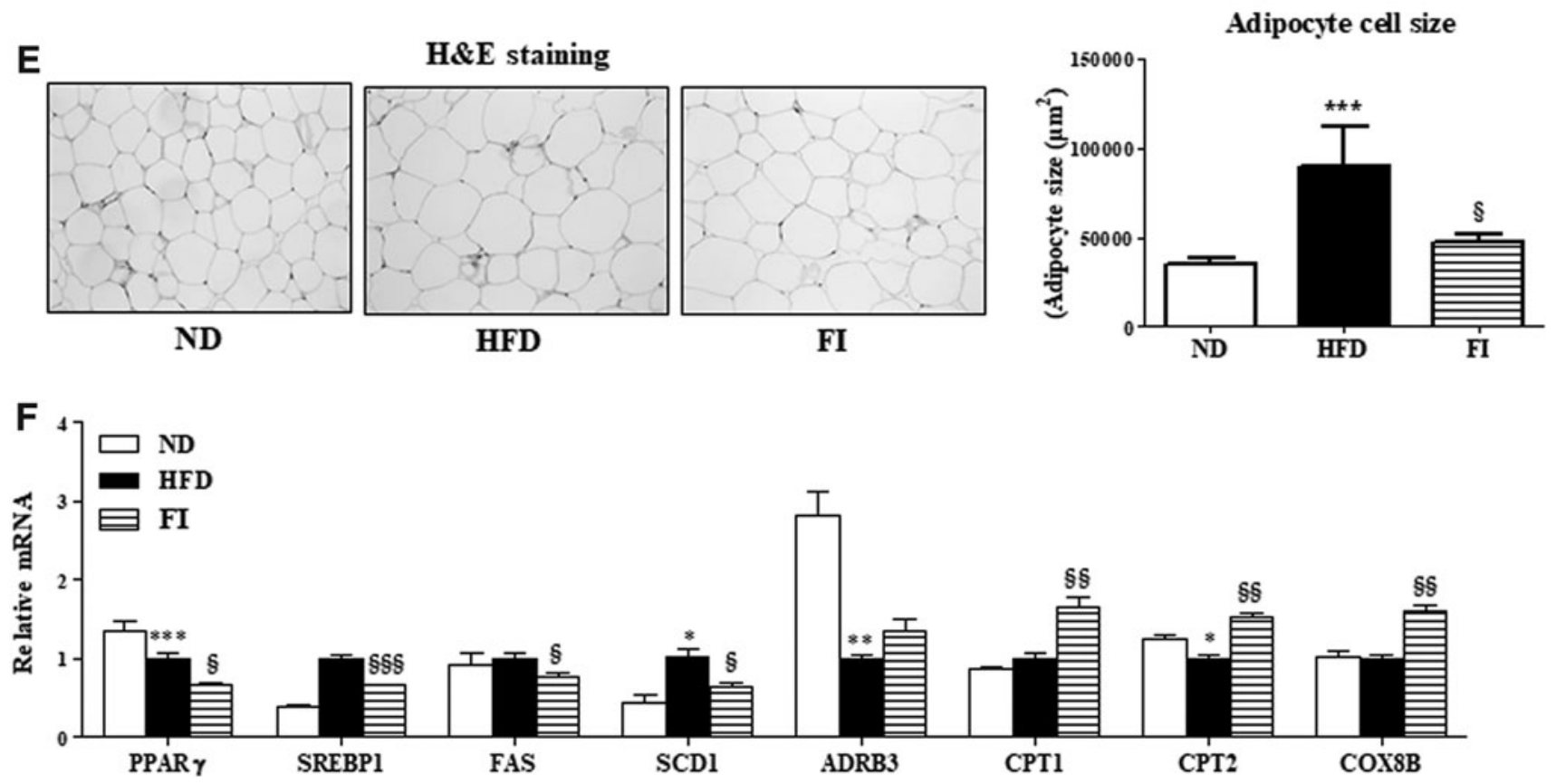

FIG. 1. Effect of fisetin supplementation for 16 weeks on body weight (A), food intake (B), FER (C), WAT weights (D), WAT morphology $(200 \times$ magnification) and adipocyte cell size $(\mathbf{E})$, and the expression of adipocyte genes $(\mathbf{F})$ in HFD-fed mice. The data are presented as means \pm SEM. ND (AIN-76) versus HFD; $* P<.05, * * P<.01, * * * P<.001$. HFD versus FI (HFD $+0.02 \%$ FI); ${ }^{\S} P<.05,{ }^{\S} P<.01,{ }^{\S \S \S} P<.001$. ADRB3, $\beta$-3 adrenergic receptor; CD36, SREBP1, sterol regulatory element-binding transcription factor 1; COX8 $\beta$, cytochrome c oxidase subunit $8 \beta$; CPT, carnitine palmitoyltransferase; FAS, fatty acid synthase; FER, food efficiency ratio; FI, fisetin; HFD, high-fat diet; ND, normal diet; PPAR $\gamma$, peroxisome proliferator-activated receptor $\gamma$; SCD1, stearoyl-CoA desaturase 1; SEM, standard error of the mean; WAT, white adipose tissue.

enzyme (e.g., CPT and $\beta$-oxidation) activities and gene (e.g., $C P T, P G C l \alpha$, and $P G C 1 \beta$ ) expressions, in the liver of HFD-fed mice (Fig. 4D, E).

Furthermore, compared with the HFD group, the levels of hepatic lipotoxicity markers, GOT and GPT, and mito- chondrial $\mathrm{H}_{2} \mathrm{O}_{2}$ and TBARS were remarkably lower in the FI group (Fig. 5A, B). The activities of plasma and hepatic PON, a hydrolytic enzyme with capability to protect against lipid oxidation, were strikingly increased by FI supplement in HFD-fed mice (Fig. 5C). FI greatly reduced 

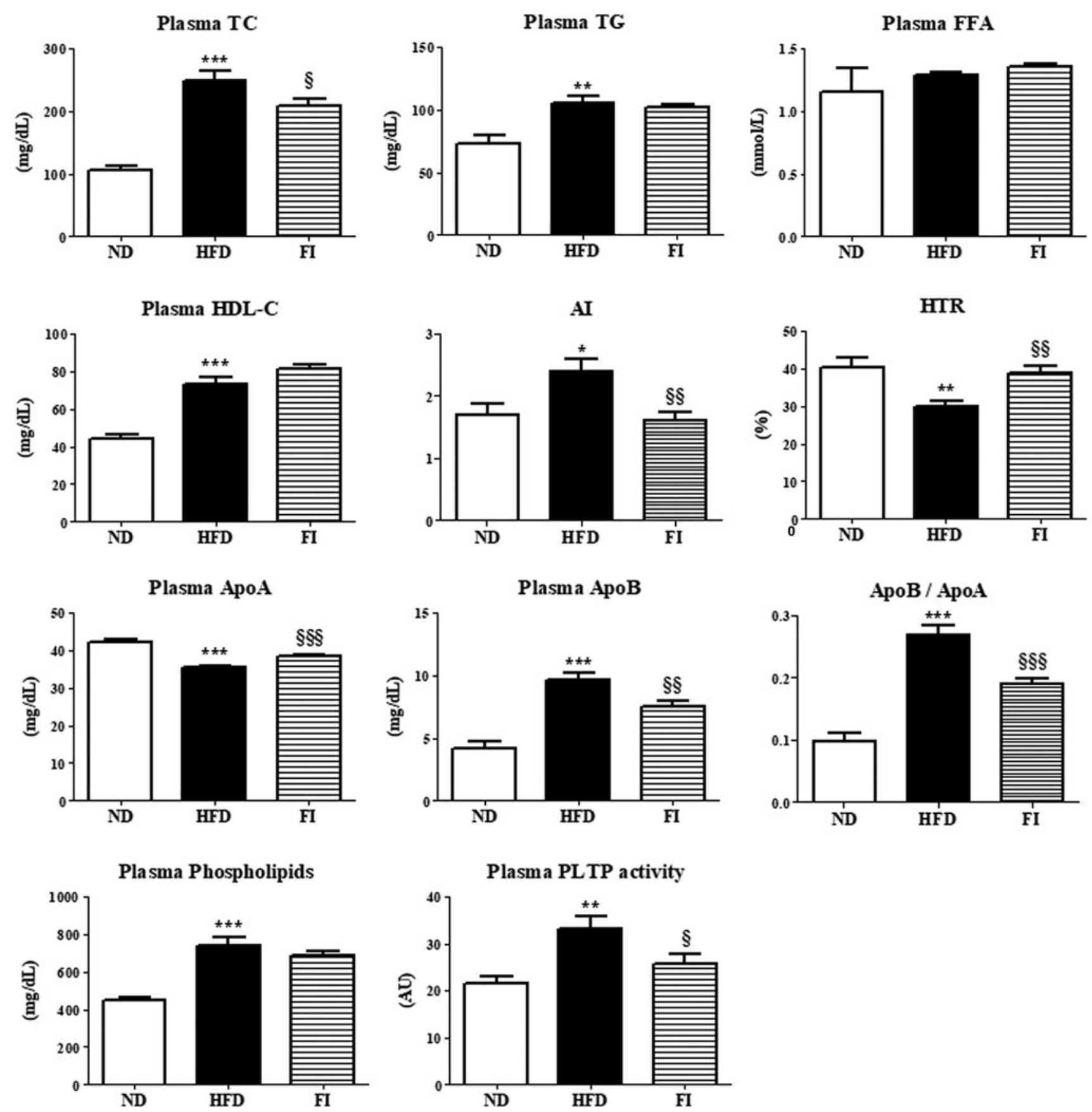

FIG. 2. Effect of fisetin supplementation for 16 weeks on plasma lipid levels in HFD-fed mice. The data are presented as means \pm SEM. ND (AIN-76) versus HFD; $* P<.05, * * P<.01, * * * P<.001$. HFD versus FI (HFD $+0.02 \%$ FI); ${ }^{\S} P<.05,{ }^{\S \S} P<.01$, ${ }^{\S \S \S} P<.001$. AI, atherogenic index; Apo, apolipoprotein; FFA, free fatty acid; HDL-C, high-density lipoprotein cholesterol; HTR, HDL-C-to-TC ratio; PLTP, phospholipid transfer protein; TC, total-cholesterol; TG, triglyceride.

plasma levels of proinflammatory cytokines, including MCP-1, TNF- $\alpha$, PAI-1, IL-6, and IFN- $\gamma$, compared to the HFD group (Fig. 5D). Moreover, FI supplementation not only significantly reduced the hepatic expression of ECM remodeling-associated genes (e.g., COL1, TIMP1, MMP2, $M M P 3$, and $M M P 9$ ), along with a decrease in mRNA expression of hepatic proinflammatory genes, TLR 4 and $I L-6$ (Fig. 5E). In addition, Masson's trichrome staining of liver and epididymal WAT sections revealed greater collagen accumulation (blue) in HFD mice, but FI showed normal architecture in the liver and very thin and tightly filled collagen sheets surrounding adipocyte (Fig. 5F). In addition to liver, FI resulted in downregulation of the adipocyte genes responsible for ECM remodeling and regulation (Colla, Mmp3, Mmp23, Tgfbi, Tgfbrl, Tlr4, Ctsa, and Ctgf) and chemokine and cytokine (Tnfrsf12a, Ccl2, Ccl11, 

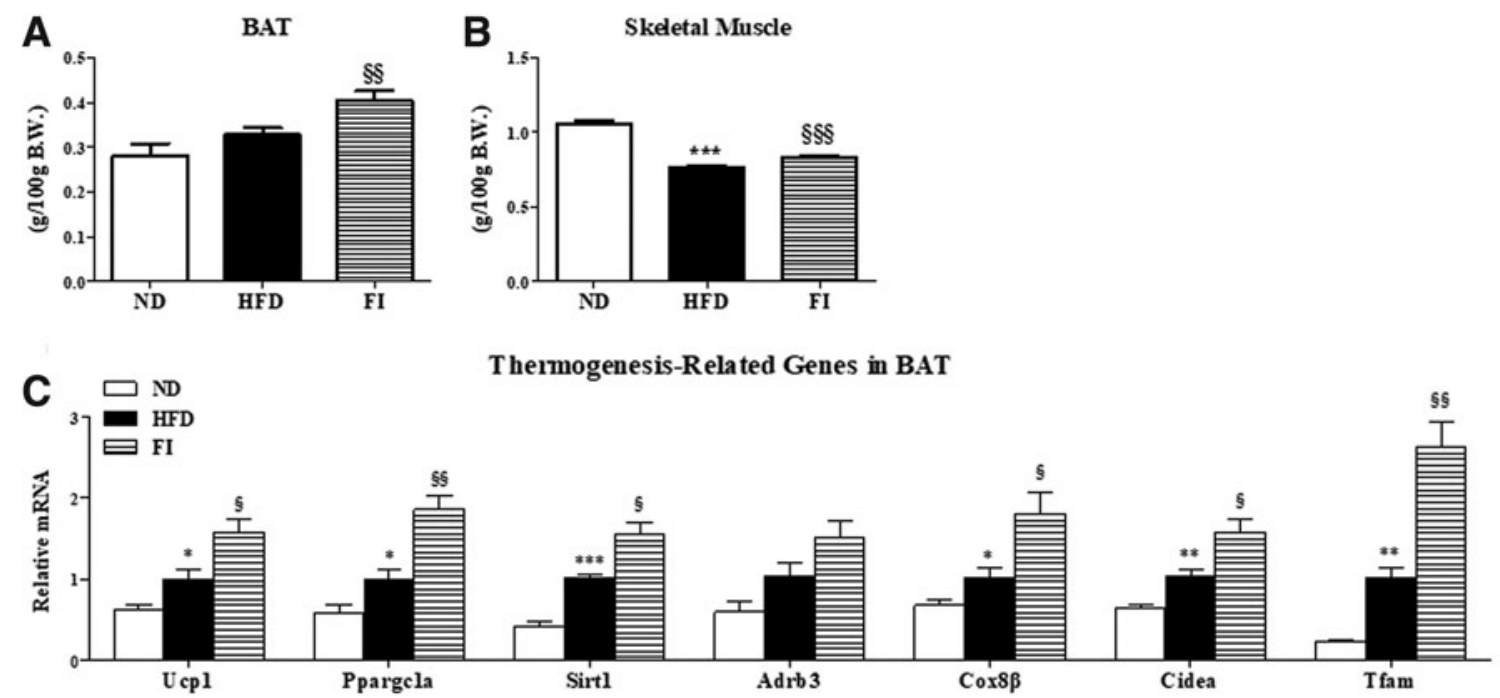

\section{TCA cycle in Skeletal Muscle}

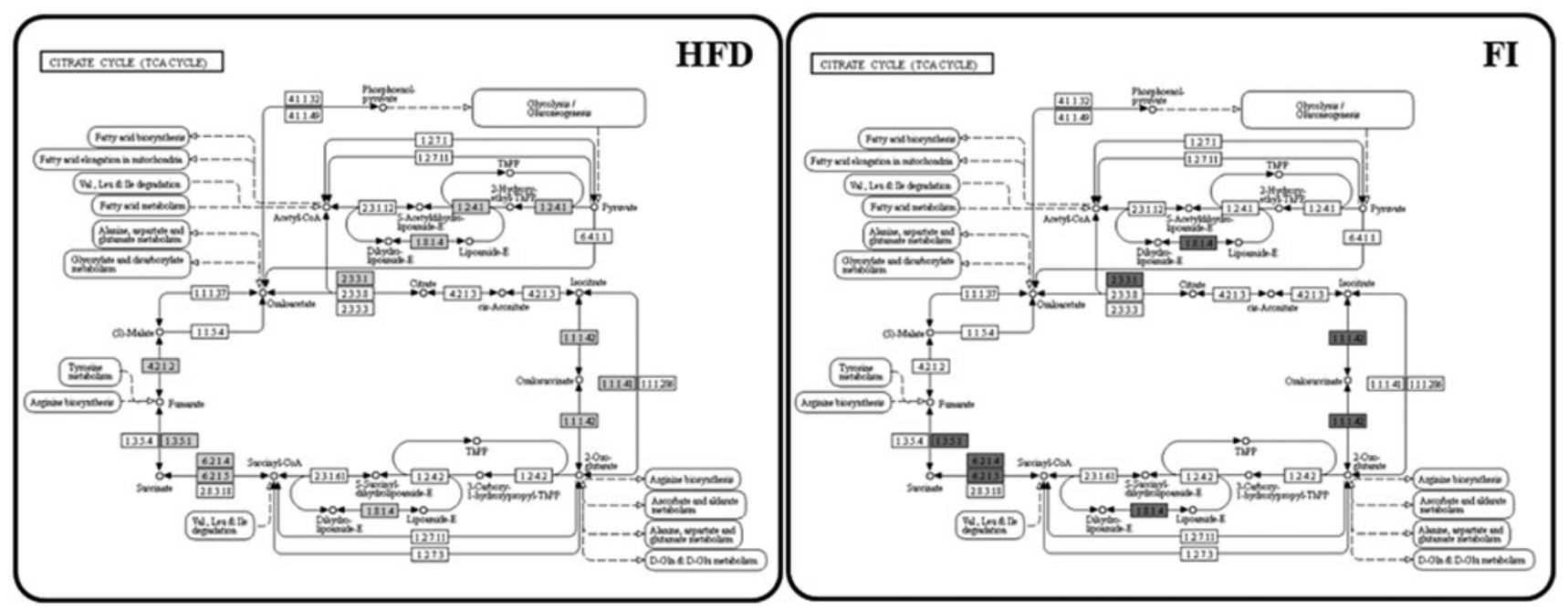

FIG. 3. Effect of fisetin supplementation for 16 weeks on the weight of BAT (A) and skeletal muscle (B), and the expression of thermogenic genes in BAT (C) and of muscle genes involved in TCA cycle (D) in HFD-fed mice. The data are presented as means \pm SEM. ND (AIN-76) versus HFD; $* P<.05, * * P<.01, * * * P<.001$. HFD versus FI (HFD $+0.02 \%$ FI); ${ }^{\S} P<.05,{ }^{\S \S} P<.01,{ }^{\S} \S P<.001$. Symbols in red indicate genes that were upregulated while those in green denote genes that were downregulated. BAT, brown adipose tissue; Cidea, cell death-inducing DFFA-like effector A; Ppargc1a, peroxisome proliferator-activated receptor $\gamma$ coactivator $1 \alpha$; Sirt1, sirtuin 1; TCA, tricarboxylic acid; Tfam, transcription factor A, mitochondrial; Ucp1, uncoupling protein 1.

Cxcl4, Cxcl14, Cxcr4, and Emrl) in comparison to the HFD group (Fig. 6A, B).

\section{Fisetin supplementation prevented IR, adipokine} dysregulation, and pancreatic islet hypertrophy

FI markedly decreased the plasma glucose and insulin (Fig. 7A, B) concentrations, and HOMA-IR index and glucose tolerance (Fig. 7C, D) relative to the HFD group. In addition, FI significantly increased the circulating GLP-1 level (Fig. 7E). Glycogen concentrations and GK and PEPCK activities were lowered, while G6Pase/GK ratio was increased by FI compared to mice fed the HFD (Fig. 7F, G). Hepatic mRNA expression also showed that FI supplementation significantly downregulated $G K, P E P C K$, and G6Pase genes, while it upregulated IRS2 gene in HFD-fed mice (Fig. 7H). Immunohistochemistry staining of the pancreatic tissue for insulin revealed that HFD-induced pancreatic islet hypertrophy was protected by FI supplementation, thereby normalizing the insulin concentration in the plasma (Fig. 7I). Moreover, FI-supplemented HFD-fed mice exhibited greatly increased level of plasma adiponectin, and thus markedly reduced a leptin/adiponectin ratio relative to the mice in the HFD group (Fig. 7J). 


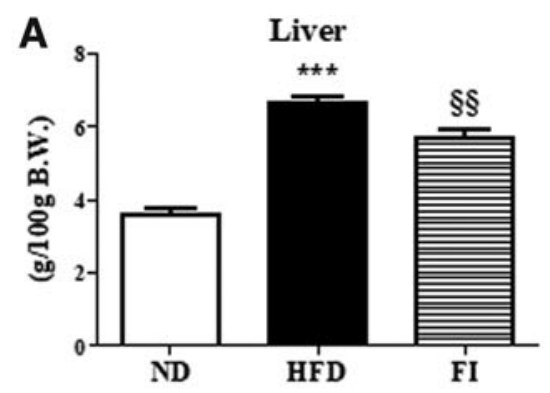

B

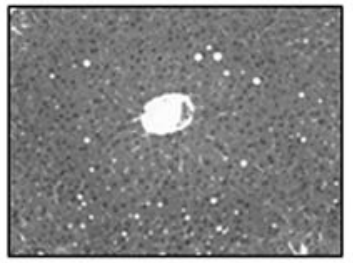

ND
H\&E staining

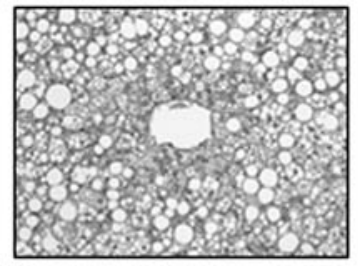

HFD

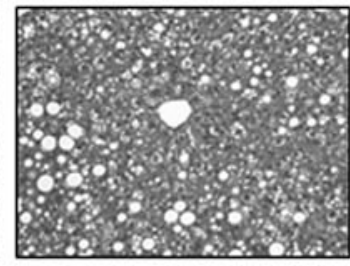

FI
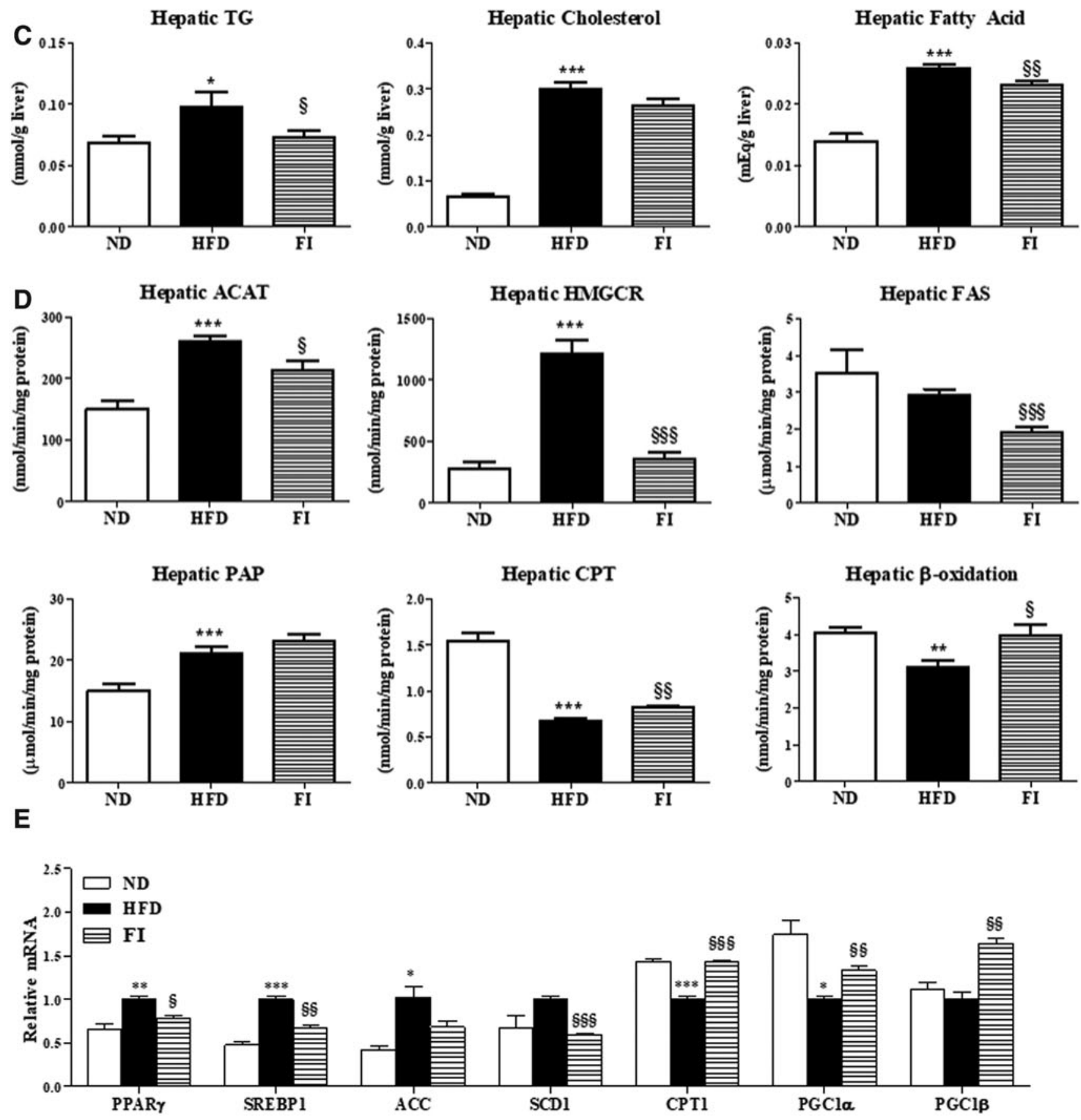

FIG. 4. Effect of fisetin supplementation for 16 weeks on liver weights (A), H\&E staining of liver $(200 \times$ magnification) (B), hepatic lipid levels (C), activities of hepatic lipid-regulating enzymes (D), and expression of hepatic genes involved in lipid metabolism (E) in HFD-fed mice. The data are presented as means \pm SEM. ND (AIN-76) versus HFD; $* P<.05$, $* * P<.01, * * * P<.001$. HFD versus FI $(\mathrm{HFD}+0.02 \% \mathrm{FI}) ;{ }^{\S} P<.05,{ }^{\S} P<<.01,{ }^{\S \S \S} P<.001$. ACAT, acyl-CoA:cholesterol acyltransferase; ACC, acetyl-CoA carboxylase; H\&E, hematoxylin and eosin; HMGCR, 3-hydroxy-3-methyl-glutarylcoenzyme A reductase; PAP, phosphatidate phosphohydrolase; PGC1, peroxisome proliferator-activated receptor $\gamma$ coactivator 1. 

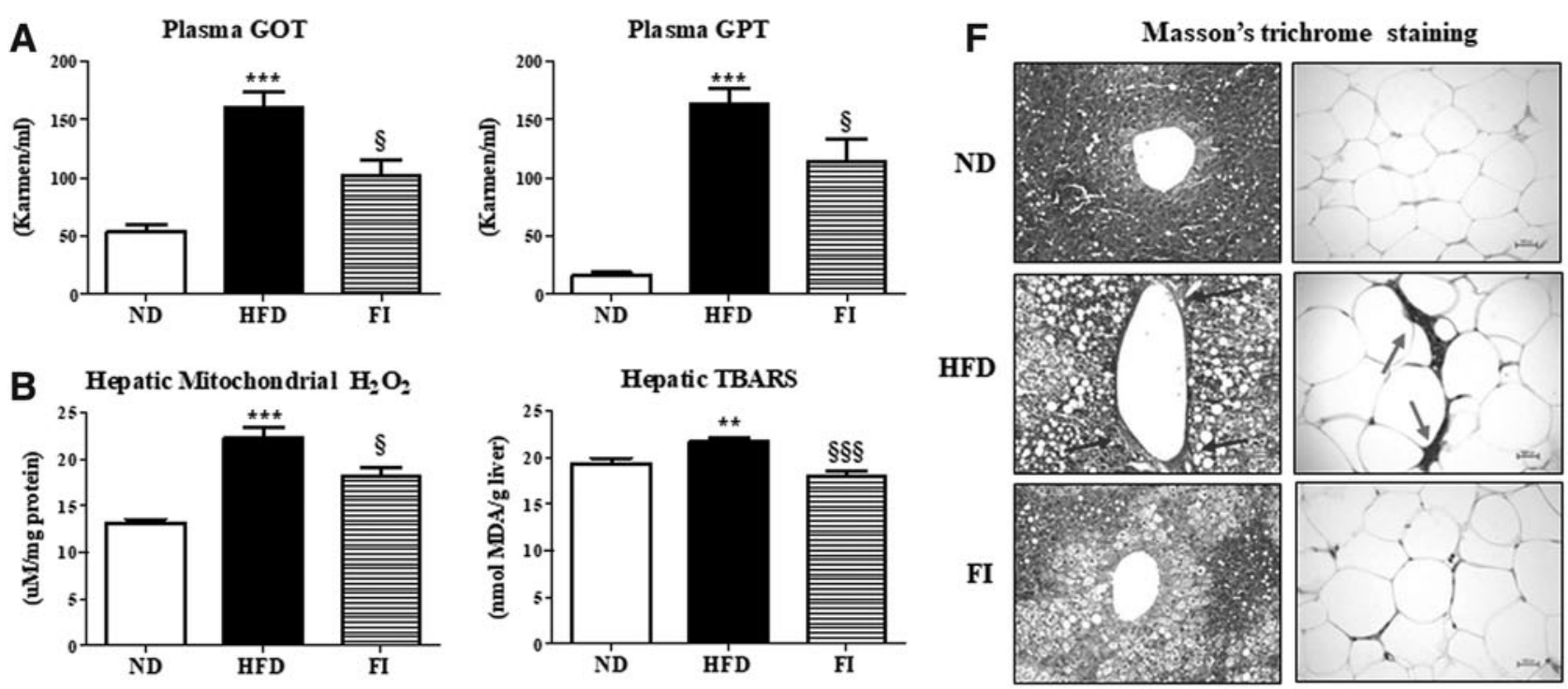

B Hepatic Mitochondrial $\mathrm{H}_{2} \mathrm{O}_{2}$
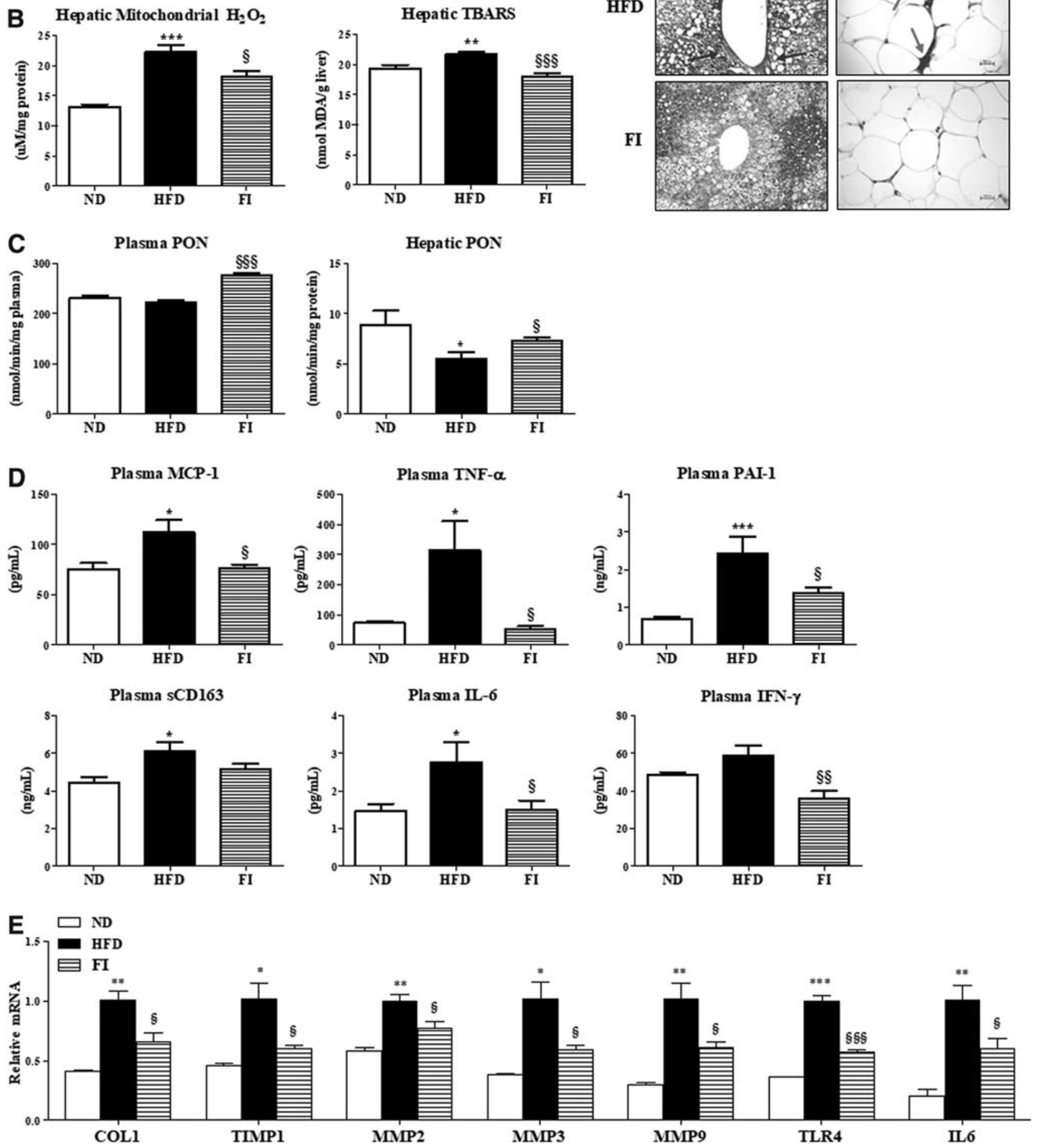

FIG. 5. Effect of fisetin supplementation for 16 weeks on plasma GOT and GPT (A), hepatic mitochondrial $\mathrm{H}_{2} \mathrm{O}_{2}$ and TBARS (B), plasma and hepatic PON (C), plasma proinflammatory cytokines (D), and expression of hepatic genes involved in ECM remodeling and inflammatory response (E) in HFD-fed mice. The data are presented as means \pm SEM. ND (AIN-76) versus HFD; $* P<.05, * * P<.01, * * * P<.001$. HFD versus FI (HFD +0.02\% FI); ${ }^{\S} P<.05$, ${ }_{\S} P<.01,{ }^{\S \S} P<.001$. Arrowheads indicate fibrillar collagens consisting mainly collagen I and III, which are stained with black. COL1, collagen 1; ECM, extracellular matrix; GOT, glutamic oxaloacetic transaminase; GPT, glutamic pyruvic transaminase; IFN- $\gamma$, interferon $\gamma$; IL, interleukin; MCP-1, monocyte chemoattractant protein-1; MMP, matrix metalloproteinase; PAI-1, plasminogen activator inhibitor 1; PON, paraoxonase; TBARS, thiobarbituric acid reactive substance; TIMP1, tissue inhibitor matrix metalloproteinase 1; TLR4, toll-like receptor 4; TNF- $\alpha$, tumor necrosis factor $\alpha$. 

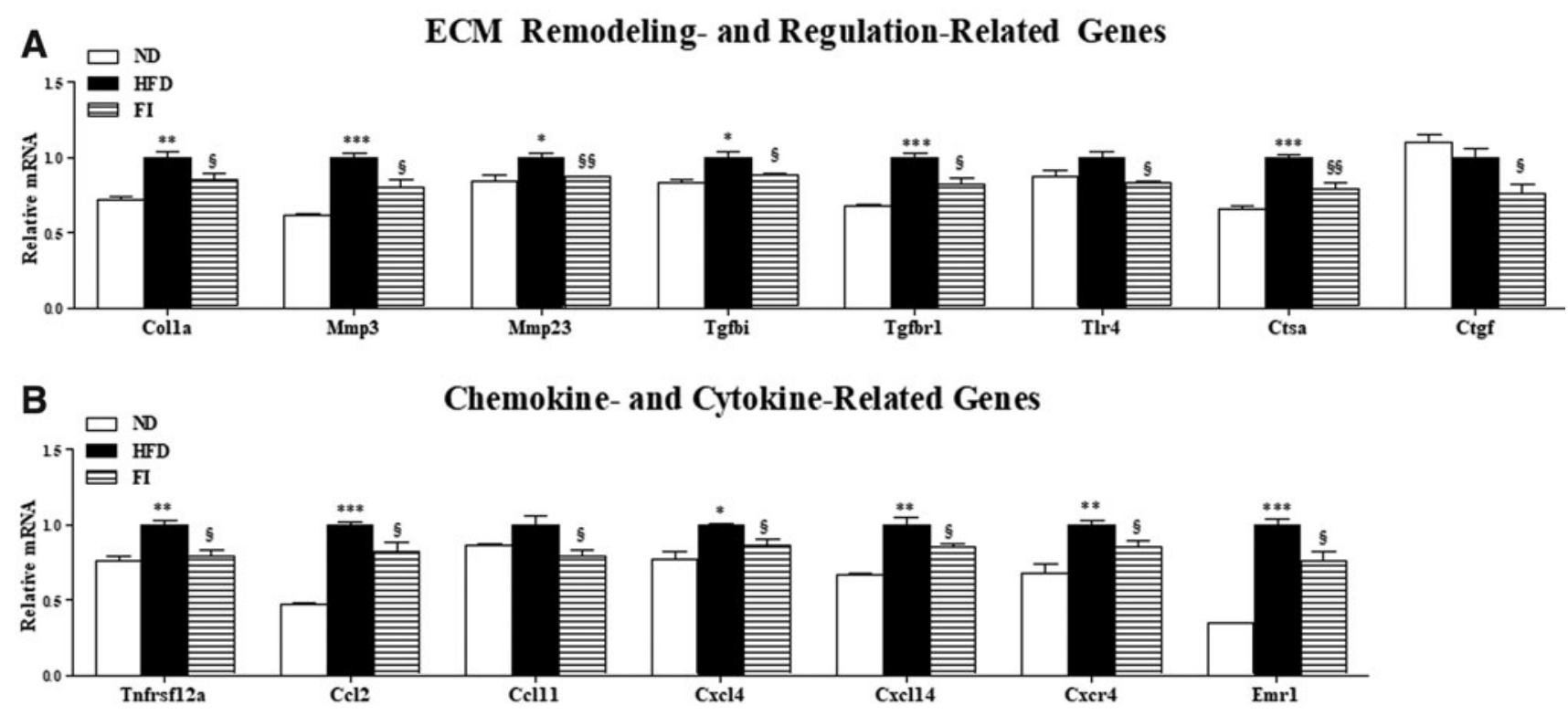

FIG. 6. Effect of fisetin supplementation for 16 weeks on the adipocyte gene transcription patterns related to ECM remodeling and ECM regulation (A) and related to Chemokine and Cytokine (B) in HFD-fed mice. The data are presented as means \pm SEM. ND (AIN-76) versus HFD; $* P<.05, * * P<.01, * * * P<.001$. HFD versus FI (HFD $+0.02 \% \mathrm{FI}) ;{ }^{\S} P<.05,{ }^{\S} P<.01$. Ccl, chemokine (C-C motif) ligand; Colla, collagen type I alpha; Ctgf, connective tissue growth factor; Ctsa, cathepsin A; Cxcl, chemokine (C-X-C motif) ligand; Cxcr4, CXC receptor; Emr1, GF-like module containing, mucin-like, hormone receptor-like sequence 1; Tgfbi, transforming growth factor, $\beta$ (TGFB) induced; Tgfbr1, TGFB $\beta$ receptor I; Tnfrsf12a, tumor necrosis factor receptor superfamily, member 12a.

\section{DISCUSSION AND CONCLUSIONS}

Being overweight and obese do not only increase adiposity and hepatic steatosis, but in these states the liver tissue accumulate excessive ECM protein, including collagen, causing nonalcoholic steatohepatitis (NASH), a severe form of NAFLD. ${ }^{34-37}$ To date, no effective drugs have been developed to treat patients with NASH and thus, in the hepatic steatosis stage, the understanding of the molecular mechanisms that cause oxidative balance impairment, lipid accumulation, fibrosis in the liver, and IR would create an opportunity to prevent and attenuate the development of NAFLD and/or NASH.

Adiposity is linked to the increased production and release of several proinflammatory cytokines and ECM components, which contribute to chronic low-grade inflammation and obesity-linked metabolic disorders such as IR and fibrosis. ${ }^{18,38,39}$ In the present study, FI ameliorated adiposity, as evidenced by a decrease in WAT weight, by increasing expression of genes involved in FA oxidation (e.g., $C P T 1, C P T 2$, and $C O X 8 \beta$ ), while decreasing the expression of genes involved in lipogenesis in adipose tissue (e.g., PPAR $\gamma, S R E B P 1, F A S$, and SCD1). Moreover, we observed that FI supplementation significantly increased BAT ad skeletal muscle weights. FI enhanced the expression of not only thermogenesis-related genes (e.g., Ucpl, Ppargcla, Sirt1, Cox $8 \beta$, Cidea, and Tfam) in BAT, but also TCA cycle-associated genes (e.g., Dld, Cs, Idh1, Idh2, Suclg1, and $S d h b$ ) in skeletal muscle, which may be related to the decreased adiposity and NAFLD in the HFD-fed obese mice. BAT and skeletal muscle are major organs that can generate heat by burning fat, which can be a potential therapeutic target for obesity and its related metabolic diseases, including NAFLD. . $^{6-8,40-44}$

The improved adiposity by FI was likely associated with a reduction of plasma proinflammatory cytokine levels (e.g., MCP-1, TNF- $\alpha$, PAI-1, IL-6) and gene expressions involved in ECM remodeling and inflammation in adipose tissue as well as liver, leading to the prevention of fibrosis. Hepatic fibrosis is a common wound healing reaction to chronic liver damage, ${ }^{45}$ involving extra deposition ECM proteins. ${ }^{46,47}$ The fibrotic ECM comprised collagens, mainly type I and type III collagens ${ }^{46}$ and overexpression of tissue inhibitors of metalloproteinases (TIMPs) and matrix metalloproteinases (MMPs), which are the main regulators of ECM turnover in hepatic fibrosis, contribute to ECM deposition and fibrosis progress. ${ }^{48,49}$ In addition, FI increased the activities of PON in plasma and liver, resulting in a decrease in excessive ROS production as evidenced by lower hepatic TBARS and mitochondrial $\mathrm{H}_{2} \mathrm{O}_{2}$ levels, which reflects improved hepatic fibrosis and IR.

The antifibrotic effects coupled with the decreased adiposity by FI supplementation were strongly linked to the improvement of NAFLD and IR. The FI group exhibited a significant decrease in hepatic lipid levels by increasing FA oxidation, and decreasing lipogenesis compared to the HFD group, which in turn caused a significant decrease in the hepatic fibrosis, which may contribute to the prevention of IR. FI prevented pancreatic islet hypertrophy, and which is known to contribute to IR by increasing insulin secretion per 

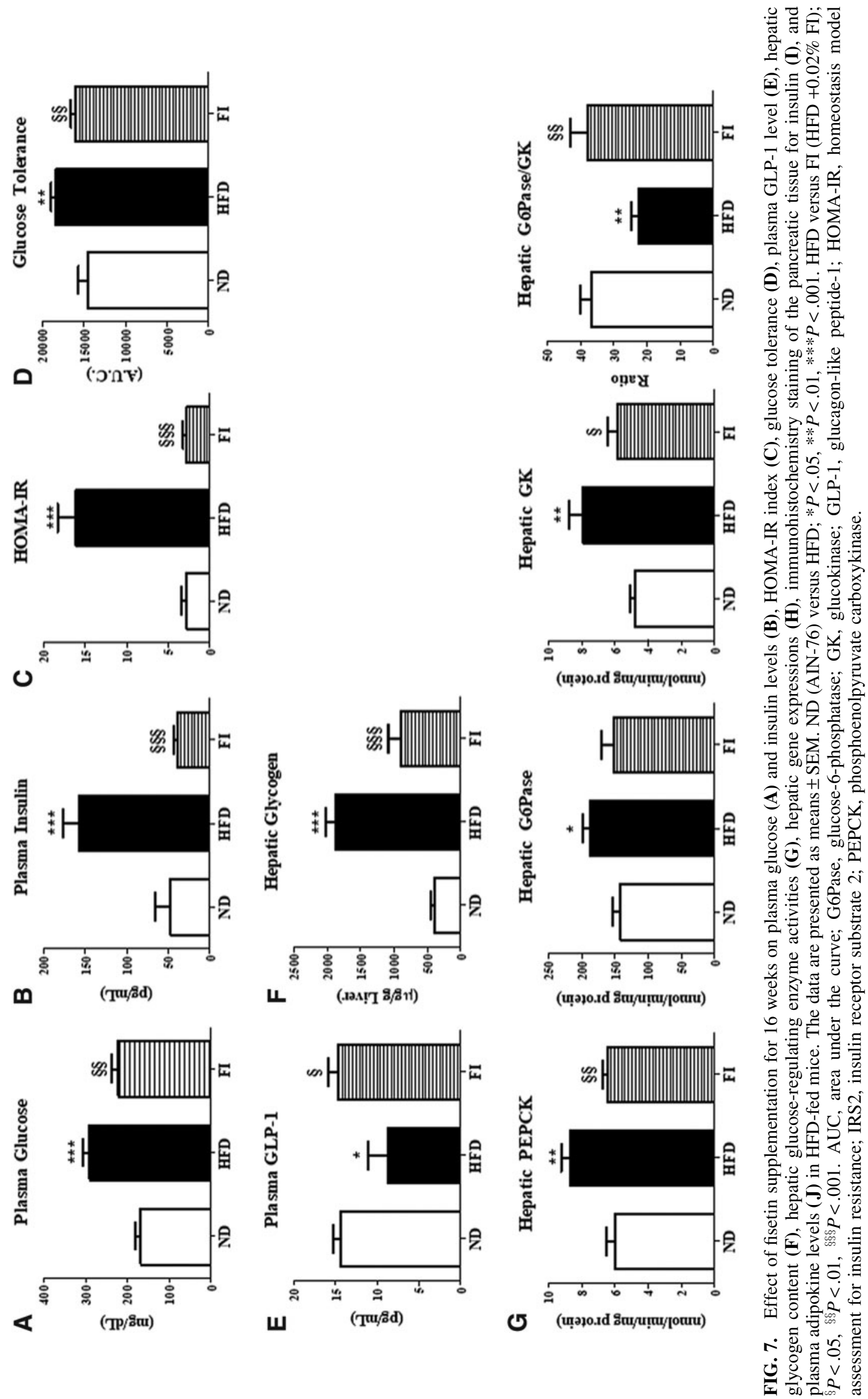

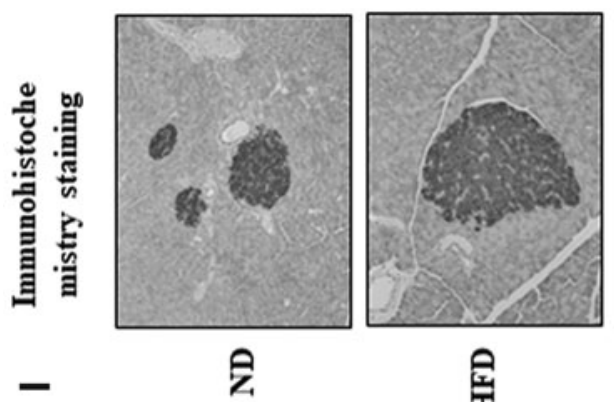

啚

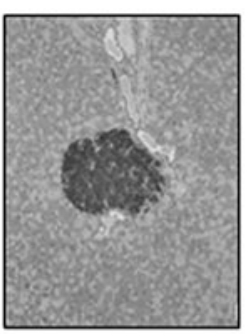

四

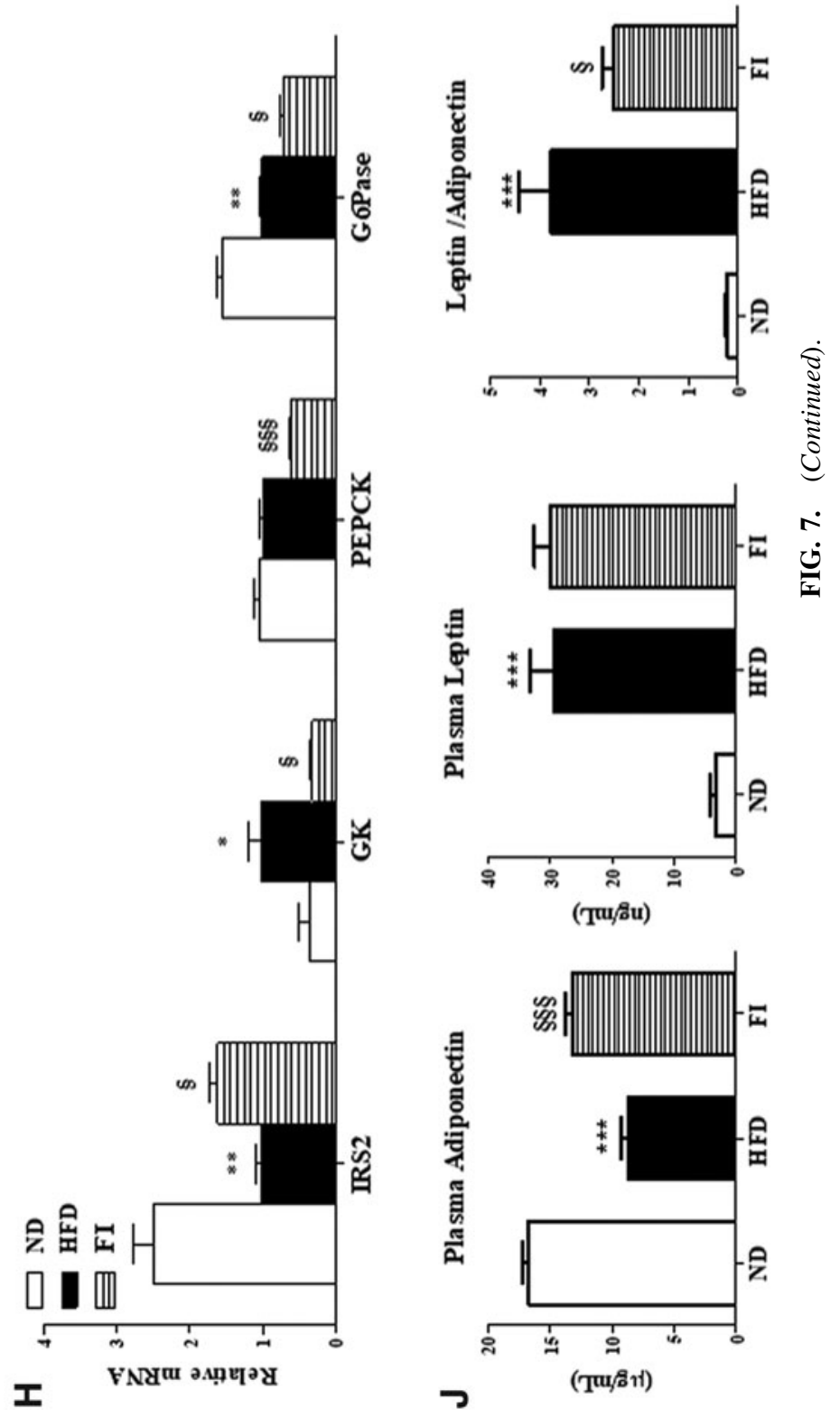


$\beta$ cell to compensate for insulin desensitization. ${ }^{50}$ Furthermore, relative to the HFD mice, FI supplementation markedly increased the plasma level of GLP-1, which can exert anti-inflammatory effects. ${ }^{51}$ Dysregulated hepatic glucose metabolism caused by an increase in gluconeogenesis also reported to contribute to the development of IR. ${ }^{52}$ Thus, the suppression of gluconeogenesis by the decreased expression and lower enzymatic activity of hepatic PEPCK appears to be associated with the enhanced insulin sensitivity observed in FI-supplemented obese mice. Moreover, FI supplementation significantly increased G6Pase/GK ratio. The G6Pase/GK ratio roughly reflects the balance between hepatic glucose release and uptake, and it is remarkably reduced in obese type II diabetics. ${ }^{53}$ In addition, we determined the plasma PLTP activity to investigate the antihyperlipidemic effect of FI supplementation. Our results indicate that FI supplementation increased the plasma PLTP activity with a simultaneous decrease in the plasma TC and AI levels. Several studies have demonstrated that plasma PLTP activity is positively associated with IR and PLTP might be a marker for NAFLD. ${ }^{54,55}$ Therefore, our results suggest that FI may have a protective role in dyslipidemia, which contributes to the development of IR and NAFLD.

In conclusion, our observations using diet-induced obese mice demonstrate a novel mechanism of FI action in improving obesity and related metabolic disorders such as hyperlipidemia, hepatic steatosis, fibrosis, and IR. Dietary FI improved hepatic steatosis by restricting lipogenesis, while promoting lipolysis in the liver. FI also prevented adiposity via an increase in the expression of genes involved in FA oxidation and the decrease in the expression of genes involved in lipogenesis in WAT, which related to the prevented NAFLD. Moreover, FI enhanced mRNA expression of thermogenesis- and TCA-cycle-related genes in BAT and skeletal muscle, respectively, along with increased BAT and skeletal muscle weights, which may lead to reduced adiposity and NAFLD in HFD-induced obese mice. This is the first study investigating the effect of FI on BAT and muscle in relationship to obesity and its metabolic diseases such as NAFLD/NASH. FI supplementation also decreased excessive ROS production by increasing PON activity, adipokine dysregulation, proinflammatory cytokine production, and ECM accumulation in the liver, which contributed to improvement of hepatic lipotoxicity and fibrosis. FI supplementation improved IR, in part, by normalizing pancreatic islet dysfunction, and it decreased hepatic gluconeogenesis and proinflammatory responses. Taken together, the present findings indicate that FI may be useful for ameliorating the deleterious effects of HFD-induced obesity and related metabolic complications such as hyperlipidemia, NAFLD, hepatic fibrosis, and IR.

\section{AUTHOR DISCLOSURE STATEMENT}

No competing financial interests exist.

\section{FUNDING INFORMATION}

This research was supported by the BK21 Plus Program (Department of Food Science and Nutrition, Kyungpook National University, 22A20130000161), and a National Research Foundation (NRF) of Korea grant funded by the Korea government (MSIP) (NRF-2020R1I1A3074694 and NRF-2019R1C1C1009530).

\section{REFERENCES}

1. Day CP, James OF: Steatohepatitis: A tale of two "hits"? Gastroenterology 1998;114:842-845.

2. Eng FJ, Friedman SL, Fibrogenesis I: New insights into hepatic stellate cell activation: The simple becomes complex. Am J Physiol Gastrointest Liver Physiol 2000;279:G7-G11.

3. Carmiel-Haggai M, Cederbaum AI, Nieto N: A high-fat diet leads to the progression of non-alcoholic fatty liver disease in obese rats. FASEB J 2005;19:136-138.

4. Schönherr E, Hausser HJ: Extracellular matrix and cytokines: A functional unit. J Immunol Res 2000;7:89-101.

5. Liu W, Baker SS, Baker RD, Zhu L: Antioxidant mechanisms in nonalcoholic fatty liver disease. Curr Drug Target 2015;16: 1301-1314.

6. Poekes L, Gillard J, Farrell GC, Horsmans Y, Leclercq IA: 19. Activation of brown adipose tissue enhances the efficacy of caloric restriction for treatment of nonalcoholic steatohepatitis. Lab Invest 2019;99:4-16.

7. Moon JS, Yoon JS, Won KC, Lee HW: 21. The role of skeletal muscle in development of nonalcoholic fatty liver disease. Diabetes Metab J 2013;37: 278-285.

8. Cai C, Song X, Chen Y, Chen X, Yu C: Relationship between relative skeletal muscle mass and nonalcoholic fatty liver disease: A systematic review and meta-analysis. Hepatol Int 2020; 14:115-126.

9. Arai Y, Watanabe S, Kimira M, Shimoi K, Mochizuki R, Kinae, $\mathrm{N}$ : Dietary intakes of flavonols, flavones and isoflavones by Japanese women and the inverse correlation between quercetin intake and plasma LDL cholesterol concentration. J Nutr 2000; 130:2243-2250.

10. Pal HC, Pearlman RL, Afaq F: Fisetin and its role in chronic diseases. Adv Exp Med Biol 2016;928:213-244.

11. Seo SH, Jeong GS: Fisetin inhibits TNF-alpha-induced inflammatory action and hydrogen peroxide-induced oxidative damage in human keratinocyte HaCaT cells through PI3K/AKT/Nrf-2mediated heme oxygenase-1 expression. Int Immunopharmacol 2015;29:246-253.

12. Jung $\mathrm{CH}$, Kim $\mathrm{H}$, Ahn J, Jeon TI, Lee DH, Ha TY: Fisetin regulates obesity by targeting mTORC1 signaling. J Nutr Biochem 2013;24;1547-1554.

13. Liou CJ, Wei CH, Chen YL, Cheng CY, Wang CL, Huang WC: Fisetin protects against hepatic steatosis through regulation of the Sirt1/AMPK and fatty acid $\beta$-oxidation signaling pathway in high-fat diet-induced obese mice. Cell Physiol Biochem 2018;49: 1870-1884.

14. Gaballah HH, El-Horany HE, Helal DS: Mitigative effects of the bioactive flavonol fisetin on high-fat/high-sucrose induced nonalcoholic fatty liver disease in rats. J Cell Biochem 2019;120: 12762-12774.

15. Cho Y, Chung JH, Do HJ, Jeon HJ, Jin T, Shin MJ: Effects of fisetin supplementation on hepatic lipogenesis and glucose me- 
tabolism in Sprague-Dawley rats fed on a high fat diet. Food Chem 2013;139:720-727.

16. Xu M, Ge C, Qin Y, Gu T, Lv J, Wang S, Ma Y, Lou D, Li Q, Hu L, Nie X, Wang M, Huang P, Tan J: Activated TNF$\alpha /$ RIPK3 signaling is involved in prolonged high fat dietstimulated hepatic inflammation and lipid accumulation: Inhibition by dietary fisetin intervention. Food Funct 2019;10: 1302-1316.

17. Kwon EY, Jung UJ, Park T, Yun JW, Choi MS: Luteolin attenuates hepatic steatosis and insulin resistance through the interplay between the liver and adipose tissue in mice with dietinduced obesity. Diabetes 2015;64:1658-1669.

18. Kwon EY, Choi MS: Luteolin targets the toll-like receptor signaling pathway in prevention of hepatic and adipocyte fibrosis and insulin resistance in diet-induced obese mice. Nutrients 2018;10:E1415.

19. Folch J, Lees M, Sloan-Stanley GH: A simple method for isolation and purification of total lipids from animal tissues. $J$ Biol Chem 1957;226:497-509.

20. Hulcher FH, Oleson WH: Simplified spectrophotometric assay for microsomal 3-hydroxy-3-methylglutaryl CoA reductase by measurement of coenzyme A. J Lipid Res 1973;14: 625-631.

21. Carl MN, Lakshmanan MR, Porter JW: Fatty acid synthase from rat liver. Methods Enzymol 1975;35:37-44.

22. Walton PA, Possmayer F: Mg2-dependent phosphatidate phosphohydrolase of rat lung: Development of an assay employing a defined chemical substrate which reflects the phosphohydrolase activity measured using membrane-bound substrate. Anal Biochem 1985;151:479-486.

23. Markwell MA, McGroarty EJ, Bieber LL, Tolbert NE: The subcellular distribution of carnitine acyltransferases in mammalian liver and kidney. A new peroxisomal enzyme. J Biol Chem 1973;248:3426-3432.

24. Lazarow P: Assay of peroxisomal b-oxidation of fatty acids. Methods Enzymol 1981;72:315-319.

25. Shapiro DJ, Nordstrom JL, Mitschelen JJ, Rodwell VW, Schimke RT: Micro assay for 3-hydroxy-3-methylglutaryl-CoA reductase in rat liver and in L-cell fibroblasts. Biochim Biophys Acta 1974; 370:369-377.

26. Gillies PJ, Rathgeb KA, Perri MA, Robinson CS: Regulation of acyl-CoA:cholesterol acyltransferase activity in normal and atherosclerotic rabbit aortas: Role of a cholesterol substrate pool. Exp Mol Pathol 1986;44:329-339.

27. Alegre M, Ciudad CJ, Fillat C, Guinovart JJ: Determination of glucose-6-phosphatase activity using the glucose dehydrogenasecoupled reaction. Anal Biochem 1988;173:185-189.

28. Davidson AL, Arion WJ: Factors underlying significant underestimations of glucokinase activity in crude liver extracts: Physiological implications of higher cellular activity. Arch Biochem Biophys 1987;253:156-167.

29. Bentle LA, Lardy HA: Interaction of anions and divalent metal ions with phosphoenolpyruvate carboxykinase. J Biol Chem 1976;251:2916-2921.

30. Seifter S, Dayton S, Muntwyler N, Muntwyler E: The estimation of glycogen with the anthrone reagent. Arch Biochem 1950;25: 191-200.

31. Wolff SP: Ferrous ion oxidation in presence of ferric ion indicator xylenol orange for measurement of hydroperoxides. Methods Enzymol 1994;233:182-189.
32. Ohkawa H, Ohishi N, Yagi K: Assay for lipid peroxides in animal tissues by thiobarbituric acid reaction. Anal Biochem 1979; 95:351-358.

33. Mackness MI, Harty D, Bhatnagar D, Winocour PH, Arrol S, Ishola M, Durrington PN: Serum paraoxonase activity in familial hypercholesterolaemia and insulin-dependent diabetes mellitus. Atherosclerosis 1991;86:193-199.

34. Reccia I, Kumar J, Akladios C, Virdis F, Pai M, Habib N, Spalding D: Non-alcoholic fatty liver disease: A sign of systemic disease. Metabolism 2017;72:94-108.

35. Heindel JJ, Newbold R, Schug TT: Endocrine disruptors and obesity. Nat Rev Endocrinol 2015;11:653-661.

36. Marchesini G, Bugianesi E, Forlani G, Cerrelli F, Lenzi M, Manini R, Natale S, Vanni E, Villanova N, Melchionda N, Rizzetto M: Nonalcoholic fatty liver, steatohepatitis, and the metabolic syndrome. Hepatology 2003;37:917-923.

37. Hazlehurst JM, Woods C, Marjot T, Cobbold JF, Tomlinson JW: Non-alcoholic fatty liver disease and diabetes. Metabolism 2016; 65:1096-1108.

38. Bourlier V, Zakaroff-Girard A, Miranville A, De Barros S, Maumus M, Sengenes C, Galitzky J, Lafontan M, Karpe F, Frayn KN, Bouloumié A: Remodeling phenotype of human subcutaneous adipose tissue macrophages. Circulation 2008;117:806815 .

39. Henegar C, Tordjman J, Achard V, Lacasa D, Cremer I, GuerreMillo M, Poitou C, Basdevant A, Stich V, Viguerie N, Langin D, Bedossa P, Zucker JD, Clement K: Adipose tissue transcriptomic signature highlights the pathological relevance of extracellular matrix in human obesity. Genome Biol 2008;9:R14.

40. Stanford KI, Middelbeek RJ, Townsend KL, An D, Nygaard EB, Hitchcox KM, Markan KR, Nakano K, Hirshman MF, Tseng YH, Goodyear LJ: Brown adipose tissue regulates glucose homeostasis and insulin sensitivity. J Clin Invest 2013;123:215-223.

41. Liu X, Zheng Z, Zhu X, Meng M, Li L, Shen Y, Chi Q, Wang D, Zhang Z, Li C, Li Y, Xue Y, Speakman JR, Jin W: Brown adipose tissue transplantation improves whole-body energy metabolism. Cell Res 2013;23:851-854.

42. Liu X, Wang S, You Y, Meng M, Zheng Z, Dong M, Lin J, Zhao Q, Zhang C, Yuan X, Hu T, Liu L, Huang Y, Zhang L, Wang D, Zhan J, Jong Lee H, Speakman JR, Jin W: Brown adipose tissue transplantation reverses obesity in $\mathrm{Ob} / \mathrm{Ob}$ mice. Endocrinology 2015;156:2461-2469.

43. Bal NC, Maurya SK, Sopariwala DH, Sahoo SK, Gupta SC, Shaikh SA, Pant M, Rowland LA, Bombardier E, Goonasekera SA, Tupling AR, Molkentin JD, Periasamy M: Sarcolipin is a newly identified regulator of muscle-based thermogenesis in mammals. Nat Med 2012;18:1575-1579.

44. Rowland LA, Bal NC, Kozak LP, Periasamy M: Uncoupling protein 1 and sarcolipin are required to maintain optimal thermogenesis, and loss of both systems compromises survival of mice under cold stress. J Biol Chem 2015;290:12282-12289.

45. Friedman SL: Liver fibrosis-from bench to bedside. J. Hepatol. 2003;38(Suppl 1):S38-S53.

46. Xu GF, Li PT, Wang XY, Jia X, Tian DL, Jiang LD, Yang JX: Dynamic changes in the expression of matrix metalloproteinases and their inhibitors, TIMPS, during hepatic fibrosis induced by alcohol in rats. World J Gastroenterol 2004;10:3621-3627.

47. Benyon RC, Iredale JP: Is liver fibrosis reversible? Gut 2000;46: 443-446. 
48. Duarte S, Baber J, Fujii T, Coito AJ: Matrix metalloproteinases in liver injury, repair and fibrosis. Matrix Biol 2015;44-46:147156.

49. Iredale JP, Thompson A, Henderson NC: Extracellular matrix degradation in liver fibrosis: Biochemistry and regulation. Biochim Biophys Acta 2013;1832:876-883.

50. Golson ML, Misfeldt AA, Kopsombut UG, Petersen CP, Gannon M: High fat diet regulation of $\beta$-cell proliferation and $\beta$-cell mass. Open Endocrinol J 2010;4. DOI: 10.2174/1874216501004010066.

51. Irwin N, Flatt PR: Evidence for beneficial effects of compromised gastric inhibitory polypeptide action in obesity-related diabetes and possible therapeutic implications. Diabetologia 2009;52:1724-1731.

52. Müller C, Assimacopoulos-Jeannet F, Mosimann F, Schneiter P, Riou JP, Pachiaudi C, Felber JP, Jéquier E, Jeanrenaud B, Tappy
L: Endogenous glucose production, gluconeogenesis and liver glycogen concentration in obese non-diabetic patients. Diabetologia 1997;40:463-468.

53. Belfiore F, Romeo F, Iannello S, Salamone C: The glucose-6phosphatase/glucokinase ratio in the liver of obese-diabetic subjects. Biochem Med Metab Biol 1989;41:77-80.

54. Kaser S, Sandhofer A, Foger B, Ebenbichler CF, Igelseder B, Malaimare L, Paulweber B, Patsch JR: Influence of obesity and insulin sensitivity on phospholipid transfer protein activity. Diabetologia 2001;44:1111-1117.

55. Dullaart RP, de Vries R, Dallinga-Thie GM, Sluiter WJ, van Tol A: Phospholipid transfer protein activity is determined by type 2 diabetes mellitus and metabolic syndrome, and is positively associated with serum transaminases. Clin Endocrinol (Oxf) 2008; 68:375-381. 